\title{
Midtrimester pregnancy loss and cervical incompetence -Is there an association with connective tissue laxity?
}

\author{
Shirley $\mathrm{Au}^{1}$, Fiona Cullinane ${ }^{1}$, Ravi Savarirayan ${ }^{2,3,4}$, Sonia R. Grover ${ }^{1,3,4,5^{*}}$ \\ ${ }^{1}$ University of Melbourne, Parkville, Australia \\ ${ }^{2}$ Genetic Services Victoria, Royal Children's Hospital, Melbourne, Australia \\ ${ }^{3}$ Dept Paediatrics, University of Melbourne, Royal Children’s Hospital, Melbourne, Australia \\ ${ }^{4}$ Murdoch Childrens' Research Institute, Royal Children’s Hospital, Melbourne, Australia \\ ${ }^{5}$ Royal Women's Hospital, Parkville, Australia \\ Email: "s.grover@bigpond.net.au
}

Received 12 October 2013; revised 10 November 2013; accepted 18 November 2013

Copyright (C) 2014 Shirley Au et al. This is an open access article distributed under the Creative Commons Attribution License, which permits unrestricted use, distribution, and reproduction in any medium, provided the original work is properly cited. In accordance of the Creative Commons Attribution License all Copyrights (C) 2014 are reserved for SCIRP and the owner of the intellectual property Shirley Au et al. All Copyright (C) 2014 are guarded by law and by SCIRP as a guardian.

\section{ABSTRACT}

Objectives: The basic mechanisms of cervical incompetence remain unknown although preliminary histological, biochemical and DNA studies suggest connective tissue pathology may be a contributing factor. Certain connective tissue disorders are known to be associated with obstetric complications. Utilising a standardised established scoring system for connective tissue laxity, this study aimed to test the relationship between clinical evidence of connective tissue laxity and cervical incompetence. Methods: This case-control study involved pregnant and non-pregnant women with a history of mid-trimester pregnancy loss in the absence of major bleeding, infection and uterine abnormalities and a control group of women with uncomplicated obstetric histories. Relevant medical details were obtained. Connective tissue laxity was assessed utilizing the Beighton scoring system. Potential confounding factors, including age, pregnancy and gestation were explored. Results: The frequency of connective tissue laxity between the cases [n $=29]$ was not statistically different from the controls $[n=58][p=$ 0.391] suggesting a lack of association between cervical incompetence and clinical evidence of connective tissue laxity. Conclusion: Although no clear evidence of connective tissue laxity was demonstrated, it is possible that cervical incompetence is associated with abnormal connective tissue. But this abnormality is different from the defect that underlies joint hypermobility and skin elasticity.

\footnotetext{
*Corresponding author.
}

\section{KEYWORDS}

Cervical Incompetence; Connective Tissue Laxity; Ehlers Danlos Syndrome; Pregnancy Complications; Beighton Score

\section{INTRODUCTION}

Cervical incompetence is a clinical diagnosis used to describe second trimester painless pregnancy loss in the absence of a precipitating cause [1]. It has an incidence of $0.05 \%-1 \%[1,2]$. The primary defect may be a structural weakness of the cervical tissue causing it to open prematurely $[3,4]$.

Recognised precipitating factors for second trimester losses include maternal exposure to diethylstilbestrol before birth [5], congenital Müllerian anomalies [6], previous cervical procedures, precipitous delivery, damage following a difficult delivery [2,7] and multiple pregnancies.

Congenital cervical factors that may contribute to preterm labour include cervical weakness due to genetic disorders affecting connective tissue such as Ehlers-Danlos [8], underlying gene mutations [9] with alterations in regulation of collagen and elastin [4,10-12]. The presence of congenital or genetic factors is supported by familial aggregation of cervical incompetence $[4,13]$.

Disorders of connective tissue are a group of heterogeneous disorders with a large spectrum of clinical presentations. In Ehlers Danlos Syndrome [EDS], a group of heritable disorders of connective tissue, there is skin hyper-elasticity, joint hypermobility, tissue fragility, altered vessel wall strength, easy bruising, and poor wound healings [14]. In EDS, obstetric complications are well docu- 
mented and include pelvic pain/instability, abnormal fetal presentation, postpartum haemorrhage due to uterine atony, preterm birth, premature rupture of membranes and third degree tears associated with slow wound healing [8].

At the mild end of the spectrum of connective tissue disorders, joint hypermobility is a benign heritable condition, with a prevalence of $10 \%-15 \%$ [15]. When assessing and diagnosing connective tissue laxity, joint mobility is an important clinical feature influenced by sex, age, gender and race [13]. The Beighton score is the most widely used scoring system for measuring joint laxity [15] and involves the assessment of the ability to perform nine simple manoeuvres (see Figure 1). It uses a 0 - 9 scoring system, with 1 point for each of the bilateral tests and 1 point for the trunk. A score of $\geq 4$ is consistent with generalized hypermobility [15].

There are only two studies on the association between connective tissue disorders and cervical incompetence. One was a case-control study involving DNA testing for specific genes and concluded that cervical incompetence is in part a genetic condition [4]. The second involved skin biopsies and concluded that a connective tissue disorder may contribute in some cases of premature rupture of membranes [16].

The hypothesis of our study is that connective tissue laxity may contribute to the occurrence of laxity in the cervix with the clinical presentation of "cervical incompetence”. The use of a simple clinical assessment for connective tissue laxity would be a useful tool to identify women with a connective tissue problem and hence a risk for cervical incompetence. We sought to clarify if this clinical assessment was useful in women with a history of cervical incompetence compared to controls.

\section{METHODOLOGY}

The study population was selected in an attempt to obtain

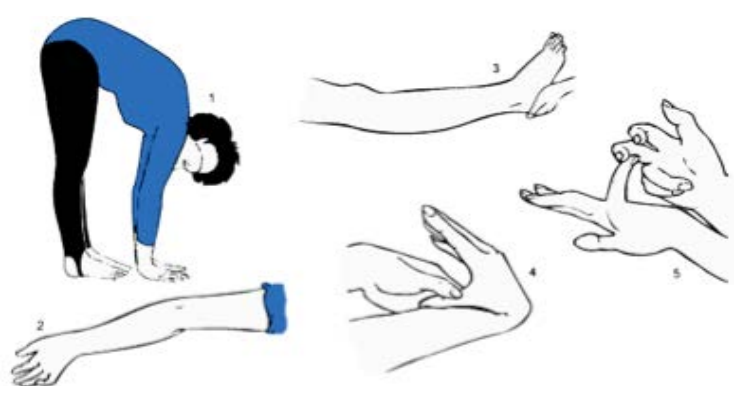

Figure 1. Beighton assessment scoring technique. (17). (1) Placing hands flat on floor with knees extended. (2) Hyperextension of elbow by 10 degrees (3) Hyperextension of knee by 10 degrees. (4) Apposition of thumb to volar aspect of forearm (5) Dorsiflexion of the fifth metacarpophalange to 90 degrees. (6) Picture taken from http://hypermobility.org/help-advice/hy-permobility-synd romes/beighton-score. a "pure group" of exceedingly high-risk women to test the hypothesis. Pregnant women attending the Preterm Labour Surveillance Clinic [PLSC] at the Royal Women's Hospital [RWH] with a history consistent with cervical incompetence without evidence of an abruption, chorioamnionitis and/or fetal abnormality, and women with an abdominal cervical suture or a cervical suture in situ were included. Women with a history of cone biopsy or uterine anomalies were excluded. Women who had a history of pregnancy beyond 32 weeks without cervical cerclage or cervical shortening were excluded as it was considered that these were less likely to represent a true congenital cervical tissue laxity problem or a true congenital incompetent cervix.

The control group consisted of either multigravid women without a history of preterm delivery attending for their routine midtrimester ultrasound; or non-pregnant multigravid women attending the hospital for contraception.

A standardised clinical history was taken involving questions regarding subjects' medical, gynaecological and obstetric background. Events that could influence the competence of the cervix were identified. Features that could represent evidence of a connective tissue disorder, such as wound breakdown, delayed healing, post partum haemorrhage as well as joint dislocation or subluxation, self reported tendency to bruise easily, poor wound healing, hernias, optical lens dislocation and a family history of such conditions were sought.

Clinical examination involved a standardized joint hypermobility score- the Beighton score (Figure 1) [17], inspection of scars and assessment of skin hyper-extensibility [by looking for extensible skin over the anterior shin, olecranon process of the elbow and anterior sternum], all performed by the same observer [SA]. The researcher's assessment technique for undertaking the Beighton score was validated by a clinical geneticist [RS]. A cut-off score of 4 was used as an indicator of hypermobility. For pregnant women, the outcome of the index pregnancy was noted, with the number of weeks of gestation at time of delivery recorded within the time constraints of the study. Continuation of the pregnancy beyond 32 weeks in the absence of a cervical suture was seen as evidence of cervical competence, particularly for the women who had not completed their pregnancy within the timelines of the study.

The study was approved by the RWH Research and Ethics Committees. Written informed consent was obtained from each participant.

Recruitment commenced in August 2003 and ended in April 2004.

\section{Statistical Analysis}

Statistical analysis was performed utilizing the program SPSS 12.0 for windows. The Fisher's exact test was used 
to analyse the Beighton score results. Additionally the Mann-Whitney test was utilized as the distribution of Beighton scores is skewed towards the lower numbers. In examining potential confounders of the Beighton score, such as age and gestation, the Spearman's rank correlation was utilized.

\section{RESULTS}

Twenty-nine study and 58 control participants were recruited. Of study participants, only 15 of 113 past [nonpregnant] patients of the PLSC fulfilled selection criteria and of 20 pregnant study participants from PLSC, 6 were later excluded as they delivered beyond thirty-two weeks without evidence of cervical incompetence. General information of the age, gravidity, parity and gestation of the study and control participants, and factors from gynaecological history potentially contributing to cervical incompetence or preterm deliveries including procedures to the cervix are shown in Table 1. Family history of potential connective tissue problems is also shown in this table. The causes of preterm deliveries in the family in both groups were mostly unknown. Only study participants reported a family history of cervical incompetence, and all were first degree female relatives.

Symptoms of connective tissue laxity in both groups consisted of single incidences of joint dislocation due to accidental injuries. For joint dislocations occurring $>1$ in a participant, one control had congenital bilateral hip dislocations, and a study participant had multiple dislocations of the same elbow. Spontaneous bruising was reported by 12 control and 9 study women. One control participant reported an umbilical hernia. No participants reported delayed wound healing, aneurysm or optical lens dislocation.

The causes of delayed wound healing in the controls' family were skin fragility and diabetes but was unknown by the particular study participant. Family history of joint flexibility was based only on the participant's subjective opinion with both groups reporting a similar proportion joint flexibility in the family. Joint dislocations in the family were all reported as individual accidents and not multiple dislocations in the same joint.

The results of the obstetric history of participants are presented in Table 2.

The number of pregnancy terminations in the study group is higher than the control group, however two cases were for fetal abnormalities.

The Beighton scores of study and control participants are shown in Figure 2. Three control [5.2\%] and two study participants [6.9\%] had a score $\geq 4$ [Fisher's exact test, $\mathrm{p}=0.543$, Odds ratio $=1.36$ [95\% CI $=(0.421$, 16.939)]. Assessment of the correlation between the Beighton score in the 2 groups using the Mann-Whitney $\mathrm{U}$ test, $\mathrm{U}(\mathrm{df})=752, \mathrm{Z}=-0.858, \mathrm{p}=0.391$.

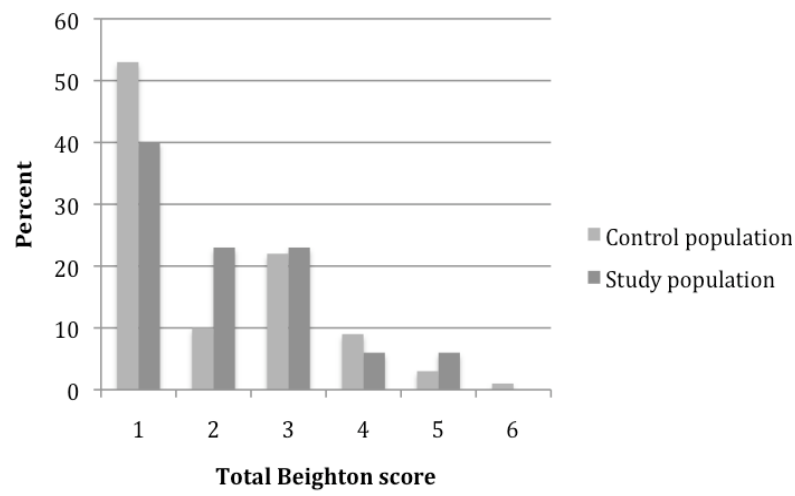

Figure 2. Distribution of Beighton score in controls and study participants.

Table 1. Demographics, family and gynaecology history of study and control populations.

\begin{tabular}{|c|c|c|}
\hline & $\begin{array}{c}\text { Control [n = 58] } \\
\text { Number [\%] }\end{array}$ & $\begin{array}{c}\text { Study }[\mathrm{n}=29] \\
\text { Number [\%] }\end{array}$ \\
\hline $\begin{array}{l}\text { Participants } \\
\text {-Pregnant }\end{array}$ & $48[82.8]^{*}$ & 14 [48.3] \\
\hline -Non pregnant & 10 [17.2] & 15 [52.7] \\
\hline & Mean [range] & Mean [range] \\
\hline Age & $32[19-53]^{\#}$ & $33[19-48]$ \\
\hline Gravida & $4[2-17]^{* *}$ & $4[1-8]$ \\
\hline Parity & $3[1-7]$ & $1[0-3]$ \\
\hline $\begin{array}{l}\text { Gestation of pregnant } \\
\text { participants }\end{array}$ & $16[7-32]^{\ddagger}$ & 22 [12 - 35] \\
\hline \multicolumn{3}{|c|}{ Gynaecological history } \\
\hline \multicolumn{3}{|l|}{ Cervical surgery for CIN } \\
\hline Total & $4[6.9]$ & $4[13.8]$ \\
\hline Cone biopsy & $1[1.7]$ & 0 \\
\hline Laser & $1[1.7]$ & $4[13.8]$ \\
\hline LEAP & $2[3.4]$ & 0 \\
\hline \multicolumn{3}{|c|}{ Family history } \\
\hline Preterm deliveries & $7[12]$ & 11 [37.9] \\
\hline Cervical Incompetence & 0 & 2 [6.9] \\
\hline Delayed wound healing & $3[5.2]$ & $1[3.4]$ \\
\hline Joint flexibility & 11 [19] & $6[20.7]$ \\
\hline Joint dislocation & $3[5.2]$ & $5[17.2]$ \\
\hline
\end{tabular}

*Proportion of pregnant participants in the control and study groups was significantly different $\left[\mathrm{Chi}^{2}=11.226,1 \mathrm{df}, \mathrm{p}=0.001\right] .{ }^{\#}$ The age in both groups was similar [Mann-Whitney U test, $\mathrm{p}=0.192$ ]. ${ }^{* * *}$ One control participant had had 15 first trimester miscarriages, with two subsequent full-term deliveries, hence the wide range of "Gravida". "The average gestation of pregnant participants in the study group was greater [Mann-Whitney U test, $p=0.005]$ as they were either recruited when they presented for cervical surveillance or with cervical incompetence. 
Table 2. Obstetric history of study and control participants.

\begin{tabular}{|c|c|c|}
\hline & Control & Study \\
\hline Total number of pregnancies & 204 & 122 \\
\hline \multicolumn{3}{|l|}{ Pregnancy Outcome } \\
\hline Alive & $148(72.1 \%)$ & $40(32.8 \%)$ \\
\hline \multicolumn{3}{|l|}{ Spontaneous First Trimester Losses } \\
\hline Spontaneous abortion ( $<20$ wk gestation) & $43(21.1 \%)$ & $30(24.6 \%)$ \\
\hline \multicolumn{3}{|c|}{ Second trimester losses } \\
\hline Still birth & 0 & $12(9.8 \%)$ \\
\hline Neonatal death & 0 & $14(11.5 \%)$ \\
\hline Death after 28 days & 0 & $1(0.8 \%)$ \\
\hline Induced abortion (Total) & $8(3.9 \%)$ & $18(14.8 \%)$ \\
\hline Mean gestation (range) & $9(5-16)$ & $8(5-21)$ \\
\hline Second trimester TOP & 1 & 3 \\
\hline Pregnancies with complications & 33 & 67 \\
\hline -Threatened Abortion & 5 & 15 \\
\hline -Preterm Premature Rupture of Membranes & 3 & 44 \\
\hline -Preterm Labour & 3 & 41 \\
\hline -Cervical Shortening & 0 & 52 \\
\hline $\begin{array}{l}\text {-Pregnancy Induced } \\
\text { Hypertension/Pre-eclampsia }\end{array}$ & 12 & 4 \\
\hline -Ante-partum Haemorrhage & 3 & 28 \\
\hline -Multiple Pregnancy & 1 & 8 \\
\hline -Fetal Abnormality & 0 & 4 \\
\hline -Post-partum Haemorrhage & 1 & 2 \\
\hline -Post-Caesarean Wound Breakdown & 11 & 15 \\
\hline Pregnancies with Cervical Cerclages & & \\
\hline Vaginal cervical cerclage & 0 & 28 \\
\hline Transabdominal cervical cerclage & 0 & 11 \\
\hline
\end{tabular}

Skin assessment did not identify any women with papyraceous scars, although one study participant had a paper-like caesarean section scar, hypermobile joints [Beighton score $=4]$ and increased skin extensibility. Hyperextensible skin on the anterior shin was detected in 1 participant from each group.

Analysis of potential confounding factors indicated there was no significant association between Beighton score and age [Spearman rank correlation, $\mathrm{p}=0.385$ ], whether participants were pregnant or not [Mann Whitney $\mathrm{U}$ test, $\mathrm{p}=0.158$ ] or gestation [Spearman's rank correlation, $\mathrm{p}=0.422]$.

\section{DISCUSSION}

While questions remain regarding the cause of cervical incompetence and the use of cervical cerclage, a technique that would allow identification of those women who would most benefit from early intervention would be helpful. Attempts to predict those at risk using obste- tric history leads to the prevention of one delivery below 33 weeks for 25 cervical sutures inserted [18]. A randomized trial using ultrasound to identify those women with a short cervix $<25 \mathrm{~mm}$ failed to demonstrate any benefit in terms of reduced preterm births $<35$ weeks [although secondary analysis showed a benefit with reduced deliveries when cervical length $<15 \mathrm{~mm}$ was used] [19]. Thus there is clearly a need for further information to guide the identification and care of women at potential risk of further preterm deliveries.

Although the question of connective tissue abnormalities in the women with an incompetent cervix has been explored at a histological, biochemical and DNA level previously, there has never been a clinical study conducted utilizing a standardized clinical test in a population of high risk women. The Beighton score is a simply test to administer and was explored as a potential assessment tool in a high risk population.

Although connective tissue laxity has not been formally studied in pregnancy, clinicians working in connective tissue disorders currently use the Beighton score in pregnant women. Despite the possibility that relaxin may generally increase connective tissue extensibility in pregnancy [20], there was no difference found between our pregnant population and Beighton score results reported in the community, with hypermobility ranging between 5\% - 43\% [15]. Likewise there was no marked difference in the pregnant and non-pregnant women in this study, suggesting that there is no major impact of pregnancy on this scoring system.

The identification of connective tissue disorders requires careful and detailed clinical history and examination. However, few features were found in either group. Our results indicated that there was no increased joint laxity in women with cervical incompetence. This may be because there is no association with congenital connective tissue laxity and that cervical incompetence is a problem in regulation or an imbalance in the components that potentiate cervical ripening. Alternatively, cervical incompetence maybe associated with abnormal connective tissue, but this is different to the defect that underlies hypermobility of joints.

\section{CONCLUSIONS}

Although the study size has been small, the study population was highly selected. Given these results, there is no evidence to suggest specific surveillance for women who have hypermobile joints and that only women with serious connective tissue disorders are at risk of pregnancy complications. Prospective studies in these women would be useful as the retrospective studies to date are likely to be biased in reporting poor outcomes.

The cause for cervical incompetence is presumably multi-factorial. For the moment, clinicians will need to 
persist with careful history and surveillance for those at risk.

\section{REFERENCES}

[1] Shennan A. and Jones, B. (2004) The cervix and prematurity: Aetiology, prediction, and prevention. Seminars in Fetal \& Neonatal Medicine, 9, 471-479. http://dx.doi.org/10.1016/j.siny.2004.09.001

[2] Harger, J.H. (2002) Cerclage and cervical insufficiency: An evidence-based analysis. Obstetrics \& Gynecology, 100, 1313-1327.

[3] Jorgensen, A.L., Alfirevic, Z., Tudur Smith, C. and Williamson, P.R. (2007) Cervical stitch (cerclage) for preventing pregnancy loss: Individual patient data meta-analysis. BJOG, 114, 1460-1476.

[4] Warren, J.E., Silver, R.M., Dalton, J., Nelson, L.T., Branch, D.W. and Porter, T.F. (2007) Collagen 1Alpha1 and transforming growth factor-beta polymorphisms in women with cervical insufficiency. Obstetrics \& Gynecology, 110, 619-624.

[5] Kaufman, R.H., Adam, E., Hatch, E.E., Noller, K., Herbst, A.L., Palmer, J.R., et al. (2000) Continued follow-up of pregnancy outcomes in diethylstilbestrol-exposed offspring. Obstetrics \& Gynecology, 96, 483-489.

[6] Rackow, B. and Arici, A. (2007) Reproductive performance of women with müllerian anomalies. Current Opinion in Obstetrics and Gynecology, 19, 229-237. http://dx.doi.org/10.1097/GCO.0b013e32814b0649

[7] Vyas, N.A., Vink, J.S., Ghidini, A., Pezzullo, J.C., Korker, V., Landy, H.J., et al. (2006) Risk factors for cervical insufficiency after term delivery. American Journal of Obstetrics \& Gynecology, 195, 787-791.

[8] Lind, J. and Wallenburg, H.C. (2002) Pregnancy and the Ehlers-Danlos syndrome: A retrospective study in a Dutch population. Acta Obstetricia et Gynecologica Scandinavica, 81, 293-300.

[9] Anum, E.A., Hill, L.D., Pandya, A. and Strauss, J.F. (2009) Connective tissue and related disorders and preterm birth: Clues to genes contributing to prematurity. Placenta, 30, 207-215.

[10] Rechberger, T., Uldbjerg, N. and Oxlund, H. (1988) Connective tissue changes in the cervix during normal pregnancy and pregnancy complicated by cervical incompetence. Obstetrics \& Gynecology, 71, 563-567.
[11] Iwahashi, M., Muragaki, Y., Ooshima, A. and Umesaki, N. (2003) Decreased type I collagen expression in human uterine cervix during pregnancy. The Journal of Clinical Endocrinology and Metabolism, 88, 2231-2235.

[12] Schlembach, D., Mackay, L., Shi, L., Maner, W.L., Garfield, R.E. and Maul, H. (2009) Cervical ripening and insufficiency: From biochemical and molecular studies to in vivo clinical examination. The European Journal of Obstetrics \& Gynecology and Reproductive Biology, 144, S70-S76.

[13] Larsson, L.G., Baum, J., Mudholkar, G.S. and Srivastava, D.K. (1993) Hypermobility: Prevalence and features in a Swedish population. British Journal of Rheumatology, 32, 116-119.

[14] Beighton, P., De Paepe, A., Steinmann, B., Tsipouras, P. and Wenstrup, R.J. (1998) Ehlers-Danlos syndromes: Revised nosology, Villefranche, 1997. Ehlers-Danlos National Foundation (USA) and Ehlers-Danlos Support Group (UK). American Journal of Medical Genetics, 77, 31-37.

[15] Remvig, L., Jensen, D.V. and Ward, R.C. (2007) Epidemiology of general joint hypermobility and basis for the proposed criteria for benign joint hypermobility syndrome: Review of the literature. Journal of Rheumatology, 34, 804-809.

[16] Hermanns-Le, T., Pierard, G. and Quatresooz, P. (2005) Ehlers-Danlos-like dermal abnormalities in women with recurrent preterm premature rupture of fetal membranes. American Journal of Dermatopathology, 27, 407-410.

[17] Hypermobility Syndrome Association (2010) Beighton score. http://www.hypermobility.org/beighton.php

[18] MRC/RCOG WPoCC (1993) Final report of the Medical Research Council/Royal College of Obstetricians and Gynaecologists multicentre randomised trial of cervical cerclage. MRC/RCOG Working Party on Cervical Cerclage. British Journal of Obstetrics and Gynaecology, 100, 516523.

[19] To, M.S., Alfirevic, Z., Heath, V.C., Cicero, S., Cacho, A.M., Williamson, P.R., et al. (2004) Cervical cerclage for prevention of preterm delivery in women with short cervix: Randomised controlled trial. Lancet, 363, 18491853.

[20] Grahame, R. (1999) Joint hypermobility and genetic collagen disorders: Are they related? Archives of Disorder Child, 80, 188-191. 